Article

\title{
A Novel Fluorescence Aptasensor Based on Magnetic Beads/Gold Nanoparticles/DNA-Stabilized Silver Nanoclusters for Detection of Salmonella Typhimurium
}

\author{
Shiqian Fu ${ }^{1,+}$, Xinyan Yang ${ }^{1,+}$, Lidong Pang ${ }^{1}$, Shasha Cheng ${ }^{1}$, Danliangmin Song ${ }^{1}$, Xue Qin ${ }^{1}$, Chaoxin Man ${ }^{2, *}$ \\ and Yujun Jiang 1 ** \\ 1 Department of Food Science, Northeast Agricultural University, Harbin 150038, China; \\ b19100103@neau.edu.cn (S.F.); 15545116996@163.com (X.Y.); a10180384@neau.edu.cn (L.P.); \\ s201001068@neau.edu.cn (S.C.); b20100126@neau.edu.cn (D.S.); b211001006@neau.edu.cn (X.Q.) \\ 2 Key Laboratory of Dairy Science, Ministry of Education, Harbin 150030, China \\ * Correspondence: cxman@neau.edu.cn (C.M.); yujun_jiang@163.com (Y.J.); Tel.: +86-451-55191820 (C.M.); \\ +86-451-55190716 (Y.J.) \\ + These authors contributed equally to this work.
}

Citation: Fu, S.; Yang, X.; Pang, L.; Cheng, S.; Song, D.; Qin, X.; Man, C.; Jiang, Y. A Novel Fluorescence Aptasensor Based on Magnetic Beads/Gold Nanoparticles/ DNA-Stabilized Silver Nanoclusters for Detection of Salmonella Typhimurium. Foods 2022, 11, 595. https: / / doi.org/10.3390/ foods11040595

Academic Editor: Andrew G. Gehring

Received: 15 January 2022

Accepted: 16 February 2022

Published: 18 February 2022

Publisher's Note: MDPI stays neutral with regard to jurisdictional claims in published maps and institutional affiliations.

Copyright: (C) 2022 by the authors. Licensee MDPI, Basel, Switzerland. This article is an open access article distributed under the terms and conditions of the Creative Commons Attribution (CC BY) license (https:// creativecommons.org/licenses/by/ $4.0 /)$.

\begin{abstract}
Salmonella Typhimurium (S. Typhimurium) is a globally distributed foodborne pathogen, which can lead to outbreaks of foodborne infectious diseases. It is essential to guarantee food safety by timely and correct detection of $S$. Typhimurium. In this investigation, an original fluorescence aptasensor was constructed to detect $S$. Typhimurium rapidly and sensitively. Through the coupling of magnetic beads, aptamer, and gold nanoparticles (AuNPs), a fluorescence quenching system with a "sandwich structure" was established. The aptamer acted as a link, and its specific binding to $S$. Typhimurium could release AuNPs from the system. Meanwhile, fluorescent DNA-stabilized silver nanoclusters (DNA-AgNCs) were synthesized. The fluorescence intensity changes caused by the fluorescence resonance energy transfer between DNA-AgNCs and AuNPs were utilized to detect $S$. Typhimurium. The purposed aptasensor exhibited high selectivity and sensitivity with a linear response to $S$. Typhimurium, ranging from $3.7 \times 10^{2}$ to $3.7 \times 10^{5} \mathrm{cfu} / \mathrm{mL}$. The limit of detection (LOD) was estimated to be $98 \mathrm{cfu} / \mathrm{mL}$ within $2 \mathrm{~h} 10 \mathrm{~min}$. In addition, this method showed excellent application for detection of $S$. Typhimurium in artificially contaminated milk, with LOD reaching $3.4 \times 10^{2} \mathrm{cfu} / \mathrm{mL}$. Therefore, the developed fluorescence aptasensor has great potential to identify $S$. Typhimurium in foodstuffs.
\end{abstract}

Keywords: DNA-stabilized silver nanoclusters; gold nanoparticles; magnetic beads; fluorescence aptasensor; Salmonella Typhimurium

\section{Introduction}

Salmonella Typhimurium (S. Typhimurium), a Gram-negative bacteria pathogen, is associated with outbreaks of foodborne infectious diseases in human and animal hosts worldwide. Its infection leads to human gastrointestinal discomforts, such as nausea, vomiting, diarrhea, and even death in severe cases [1]. The major source of $S$. Typhimurium is the consumption of contaminated eggs, vegetables, fruits, poultry, meat, and milk [2]. The presence of this organism in food poses a severe threat to public safety. Currently, several methods have been proposed to identify $S$. Typhimurium, including traditional culture, molecular detection, and immunological detection. However, each method has its own limitations. The traditional culture method is the most commonly used detection technique, but it is time-consuming and cost-intensive [3]. Several molecular detection methods, such as PCR and LAMP, require expensive instruments and complex DNA extraction procedures [4]. Immunological assays based on antigen-antibody interaction include the structures of antibodies that are deformed under high temperature and batch-to-batch 
variation in functionality [5]. Hence, it is quite essential to set up a rapid, convenient, and accurate method of detection to ensure food safety, especially for the screening of specific recognition elements of $S$. Typhimurium.

Aptamers are short, single-stranded DNA or RNA molecules. By folding into distinct secondary and tertiary structures, they can combine with strong affinity and selectivity to a broad set of targets, such as small molecules and single cells [6]. As new recognition elements, aptamers offer significant benefits when compared with antibodies used in molecular recognition, including small size, quick synthesis, easy modification, longterm stability, non-toxicity, and low immunogenicity [7]. Some studies have developed aptasensors to test $S$. Typhimurium based on different analytical techniques [8-11]. Among them, the fluorescent aptasensor is frequently used because of its high sensitivity and accuracy. Most fluorescent molecular beacons, however, such as common organic dyes and quantum dots, have poor photostability, cell toxicity, and large physical size [12]. Thus, a more stabilized and productive fluorescence aptasensor is urgently necessary.

DNA-stabilized silver nanoclusters (DNA-AgNCs), an advanced category of fluorescent nanostructures, have drawn people's attention extensively on account of their good photostability, excellent biocompatibility, ultrasmall size, high quantum yield, low toxicity, and tunable wavelength. In recent years, DNA-AgNCs, serving as fluorescent probes, have been widely used in biosensors to detect DNA [13], proteins [14], metal ions [15], microRNA [16], small molecules [17], and tumor cells [18]. In addition, gold nanoparticles (AuNPs) are extensively utilized to construct biosensors because of their great biocompatibility, unique features, and unique optical properties [19]. Most importantly, AuNPs have ultrahigh fluorescence quenching capability upon the fluorescent molecular beacons [20]. Some studies about combining the AuNPs and DNA-AgNCs to design fluorescence aptasensors have been reported [21,22]. In these analyses, fluorescence quenching would happen while the fluorophores are linked with AuNPs, resulting in fluorescence resonance energy transfer (FRET) from the organic donor to the AuNPs acceptor.

In this article, an original fluorescence aptasensor was constructed based on magnetic beads / AuNPs/DNA-AgNCs to detect $S$. Typhimurium. Magnetic beads conjugated with complementary DNA (cDNA), aptamer, and AuNPs probe formed a fluorescence quenching system, so DNA-AgNCs can be adsorbed and quenched when added to the system. However, when $S$. Typhimurium was present, its specific recognition with the aptamer led to the release of AuNPs in the fluorescence quenching system, thereby inhibiting the fluorescence quenching of DNA-AgNCs. Therefore, the designed novel fluorescence aptasensor was based on the change in fluorescence intensity to attain a simple, rapid, and sensitive identification of $S$. Typhimurium.

\section{Materials and Methods}

\subsection{Materials}

Sodium tetrahydridoborate $\left(\mathrm{NaBH}_{4}\right), \mathrm{HAuCl}_{4} \cdot 3 \mathrm{H}_{2} \mathrm{O}$, trisodium citrate, and silver nitrate $\left(\mathrm{AgNO}_{3}\right)$ were from Aladdin Reagent Co., Ltd. (Shanghai, China). Streptavidinmodified magnetic beads (SMBs, $10 \mathrm{mg} / \mathrm{mL}, 1 \mu \mathrm{m}$ Dynabeads $^{\mathrm{TM}}$ MyOne $^{\mathrm{TM}} \mathrm{T} 1$ ) were purchased from Invitrogen Biotechnology Co., Ltd. (Carlsbad, CA, USA). All other reagents used in this trial were of analytical grade, which were obtained from Sinopharm Chemical Reagent Co., Ltd. (Shanghai, China). UHT-sterilized milk samples were obtained from a local market (Harbin, China). Oligonucleotide sequences were synthesized by Sangon Biotech Co., Ltd. (Shanghai, China) and purified by HPLC, which are shown in Table 1. Following this, $2 \times \mathrm{B} \& W$ buffer containing $10 \mathrm{mM}$ Tris- $\mathrm{HCl}$ (pH 7.5), $1 \mathrm{mM}$ EDTA, and $2 \mathrm{M} \mathrm{NaCl}$ were prepared. Meanwhile, PBS solution $(10 \mathrm{mM}$ phosphate buffer saline, $\mathrm{pH}$ 7.4), PB solution (20 mM phosphate buffer, $\mathrm{pH} 7.4)$, A buffer (10 mM phosphate buffer, 0.1\% SDS, pH 7.6), and B buffer (1 mM phosphate buffer, 0.01\% SDS, $2 \mathrm{M} \mathrm{NaCl,} \mathrm{pH} \mathrm{7.6)}$ were also prepared for follow-up study. 
Table 1. All oligonucleotide sequences used in this investigation.

\begin{tabular}{cc}
\hline Primer & Sequence $\mathbf{( 5}^{\prime} \mathbf{- 3}^{\prime} \mathbf{)}$ \\
\hline Aptamer & TATGGCGGCGTCACCCGACGGGGACTTGACATTATGACAG \\
cDNA1 & biotin-CTGTCATAATGTCAAGTCC \\
CDNA2 & GTCGGGTGACGCCGCCATA-SH \\
DNA & AGTGGAAAAACCCCCCCCCCC \\
\hline
\end{tabular}

\subsection{Instrumentation}

A SpectraMax i3x multifunctional microplate reader from Molecular Devices Co., Ltd. (San Jose, CA, USA) was used to measure the absorption and fluorescence spectra. Transmission electron microscopy (TEM; HT7800, Hitachi, Japan) was applied to record the images of AuNPs. X-ray photoelectron spectroscopy (XPS; ESCALAB 250Xi) from Thermo Scientific (Waltham, MA, USA) and Talos F200X TEM (FEI Company, Hillsboro, OR, USA) were utilized to assess the prepared DNA-AgNCs.

\subsection{Bacterial Strains and Cultivation Conditions}

S. Typhimurium ATCC 14028 was selected to conduct the experiment as the target bacteria, and Staphylococcus aureus (S. aureus) ATCC 25923, Escherichia coli O157:H7 (E. coli O157:H7) ATCC 25922, Shigella flexneri (S. flexneri) CMCC 51572, Cronobacter sakazakii (C. sakazakii) ATCC 29544, Bacillus cereus (B. cereus) CMCC 63303, Vibrio parahaemolyticus (V. parahaemolyticus) ATCC 17802, and Listeria monocytogenes (L. monocytogenes) ATCC 19114 served as non-target strains. All the above bacterial strains were preserved in our lab and were pre-enriched in LB broth and shaken at $37^{\circ} \mathrm{C}$ overnight. Then, the cultured bacterial solution was serially tenfold diluted. The appropriate dilutions were coated onto LB agar plates. After cultivation overnight at the same temperature, the colonies were measured to calculate the live count. Three parallel boards were performed for each dilution.

\subsection{Preparation of SMBs-cDNA1 Complex}

The preparation of SMBs-cDNA1 complex was reported in our previous work [23]. First, $1 \mathrm{mg}$ of SMBs was washed three times with $1 \times \mathrm{B} \& W$ buffer, and redispersed in $200 \mu \mathrm{L}$ of $2 \times \mathrm{B} \& \mathrm{~W}$ buffer. Then, $200 \mu \mathrm{L}$ of $2 \mu \mathrm{M}$ cDNA1 was added and reacted at $37^{\circ} \mathrm{C}$ with shaking for $1 \mathrm{~h}$. After washing with $1 \times \mathrm{B} \& W$ buffer, the SMBs-cDNA1 complex was resuspended in PBS solution. Finally, the SMBs-cDNA1 complex with a final concentration of $5 \mu \mathrm{g} / \mu \mathrm{L}$ was stocked at $4{ }^{\circ} \mathrm{C}$ for future trial.

\subsection{Production of the AuNPs and AuNPs-cDNA2 Probe}

The synthesis of AuNPs was conducted according to previous literature [24] with some modifications. Briefly, under vigorous magnetic stirring, $99 \mathrm{~mL}$ of ultrapure water was heated to boiling, before adding $1 \mathrm{~mL}$ of $\mathrm{HAuCl}_{4}$ solution $(1 \%$, wt/wt). After heating to boiling, under magnetic stirring, $2.2 \mathrm{~mL}$ of sodium citrate solution $(1 \%$, wt/wt) was added into the mixture, then boiled and stirred for $15 \mathrm{~min}$ until the color turned red. After that, the AuNPs solution was cooled to $25^{\circ} \mathrm{C}$ and centrifuged at $12,000 \times g$ for 20 min at $4{ }^{\circ} \mathrm{C}$. After removal of the supernatant, the prepared AuNPs were dispersed in ultrapure water and stored at $4{ }^{\circ} \mathrm{C}$ for further experiments.

The AuNPs-cDNA2 probe was prepared as reported previously [25]. In brief, $8 \mu \mathrm{L}$ of thiol-modified cDNA2 $(100 \mu \mathrm{M})$ was mixed with $1 \mathrm{~mL}$ of AuNPs solution, followed by incubating at $50{ }^{\circ} \mathrm{C}$ for $22 \mathrm{~h}$. Later, $100 \mu \mathrm{L}$ of A buffer was put into the mixture. After incubation at $50{ }^{\circ} \mathrm{C}$ for $60 \mathrm{~min}$, B buffer was added gently for reaction until the $\mathrm{NaCl}$ concentration arrived at $0.14 \mathrm{M}$. The solution was centrifugated at $12,000 \times \mathrm{g}$ for $20 \mathrm{~min}$ at $4{ }^{\circ} \mathrm{C}$ to remove the excessive cDNA2. Finally, the obtained AuNPs-cDNA2 probe was resuspended in $200 \mu \mathrm{L}$ of ultrapure water and stored in the dark at $4{ }^{\circ} \mathrm{C}$ prior to use. 


\subsection{Synthesis of DNA-AgNCs}

The synthesis of DNA-AgNCs was performed on the basis of the method reported in previous literature [26] with little change. First, $89 \mu \mathrm{L}$ of PB solution containing $1.5 \mathrm{nmol}$ DNA was added to $90 \mu \mathrm{M} \mathrm{AgNO} 3(6 \mu \mathrm{L}, 1.5 \mathrm{mM})$, and then incubated in the dark at $4{ }^{\circ} \mathrm{C}$ for $20 \mathrm{~min}$. Afterwards, $75 \mu \mathrm{M} \mathrm{NaBH} 4(5 \mu \mathrm{L}, 1.5 \mathrm{mM})$ was dispersed into the mixture, followed by vigorous shaking for $1 \mathrm{~min}$. The mixed solution was incubated in the dark at $4{ }^{\circ} \mathrm{C}$ for $12 \mathrm{~h}$ before use.

\subsection{Fluorescence Aptasensor Assay of S. Typhimurium}

Briefly, the fluorescence quenching system was prepared by mixing $2.5 \mathrm{nM}$ Apt with $30 \mu \mathrm{g}$ of SMBs-cDNA1 complex and $15 \mu \mathrm{L}$ of AuNPs-cDNA2 probe in $100 \mu \mathrm{L}$ of PBS solution, followed by incubation at $37^{\circ} \mathrm{C}$ for $90 \mathrm{~min}$. After removal of the supernatant by magnetic separation, the SMBs-Apt-AuNPs were washed with PBS solution, and combined with $200 \mu \mathrm{L}$ of different concentrations of $S$. Typhimurium, before being incubated at $37^{\circ} \mathrm{C}$ for $1 \mathrm{~h}$. The supernatant was discarded and the sediment was resuspended in $80 \mu \mathrm{L}$ of ultrapure water. Subsequently, $20 \mu \mathrm{L}$ of DNA-AgNCs was added to the solution. After $10 \mathrm{~min}$, the fluorescence intensity of DNA-AgNCs was recorded by a microplate reader (Excitation at $576 \mathrm{~nm}$; Emission at $643 \mathrm{~nm}$ ). F0 and F indicated the fluorescence intensity of the absence and presence of $S$. Typhimurium, respectively.

\subsection{Sensitivity Assessment in Milk Samples}

To investigate the practicability of the designed aptasensor in real samples, the detection sensor was applied to detect $S$. Typhimurium in artificially contaminated milk. The UHT sterilized milk samples were tested to confirm the absence of $S$. Typhimurium according to ISO 6579-1: 2017 [27]. The spiked milk samples were arranged by adding different concentrations of $S$. Typhimurium to reach final concentrations ranging from $7.6 \times 10^{1}$ to $7.6 \times 10^{7} \mathrm{cfu} / \mathrm{mL}$. Then, the upper whey and fat in the spiked samples were removed by centrifugation, and the pellet was resuspended in the same volume of PBS solution. Finally, the spiked milk samples were analyzed through the experimental process of the proposed fluorescent aptasensor.

\section{Results and Discussion}

\subsection{Principle of Detection Method}

The schematic diagram of the fluorescence aptasensor for testing $S$. Typhimurium is shown in Scheme 1. The designed fluorescence quenching system was a sandwich structure including a SMBs-cDNA1 complex, an aptamer, and a AuNPs-cDNA2 probe. The establishment of the system was mainly based on the complementary hybridization between cDNA1 (cDNA2) and the aptamer. In addition, DNA-AgNCs served as the fluorescence signal for this assay. The template used to synthesize DNA-AgNCs consisted of two functional selections. The first selection, containing the cytosine oligonucleotide $\mathrm{dC}_{12}$, could bind with $\mathrm{Ag}^{+}$followed by $\mathrm{NaBH}_{4}$ reduction to prepare DNA-AgNCs. Some studies have used $\mathrm{dC}_{12}$ as an effective basic substance to composite DNA-AgNCs [28-30]. The second selection, which included a consecutive adenine (Poly A) and its binding to the AuNPs, quenched the fluorescence of AgNCs using FRET. It has been confirmed that single-stranded DNA could be adsorbed onto the surface of AuNPs readily through van de Waals and hydrophobic interactions [31]. Among the four bases, base A has the highest relative affinity for AuNPs [32]. 


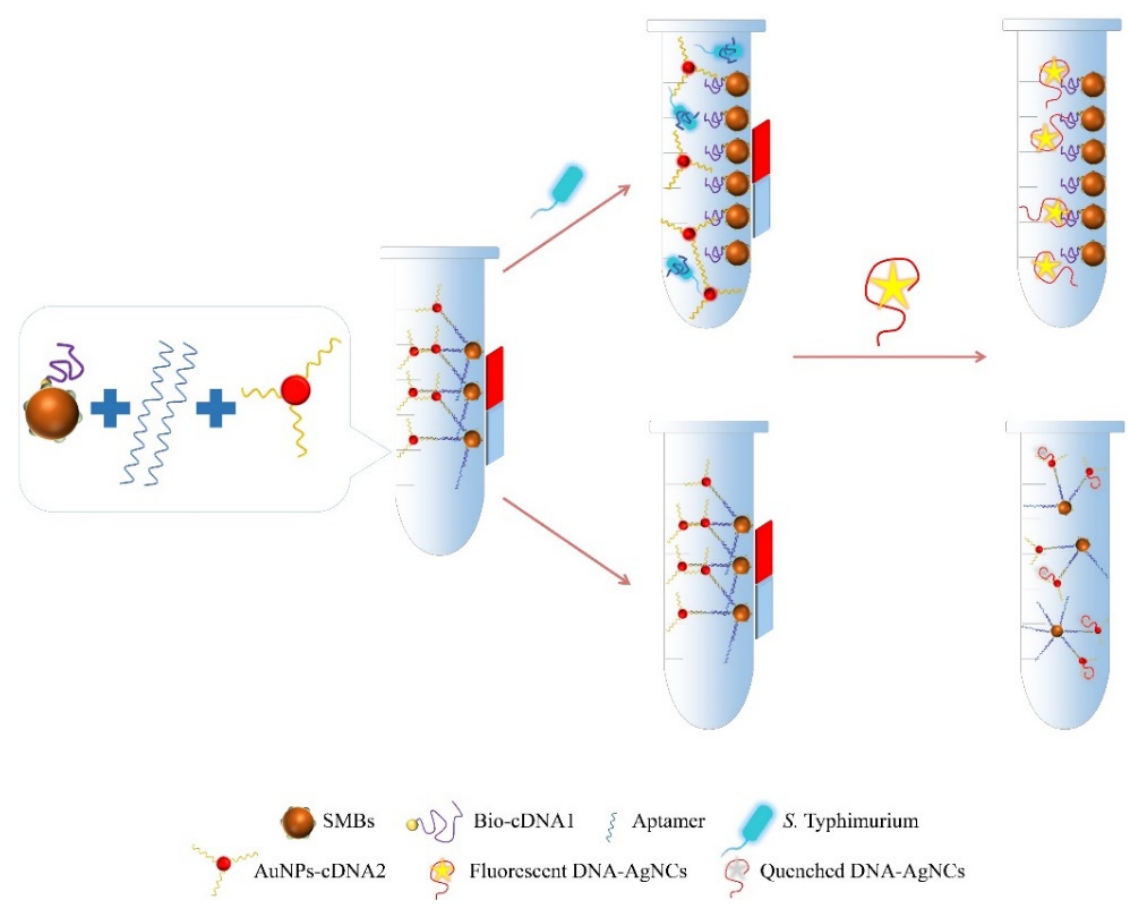

Scheme 1. Schematic diagram of the fluorescence aptasensor for testing of Salmonella Typhimurium by magnetic beads/gold nanoparticles/DNA-stabilized silver nanoclusters.

First, the SMBs-cDNA1 complex, the aptamer, and the AuNPs-cDNA2 probe were incubated to form a fluorescence quenching system. When Salmonella was present in the solution, the aptamer specifically coupled with the target goal, leading to the discharge of AuNPs-cDNA2 probe. Therefore, when DNA-AgNCs were added, the complex could fluoresce and not be quenched. However, the SMBs-Apt-AuNPs system inhibited the fluorescence of DNA-AgNCs when $S$. Typhimurium was absent.

\subsection{Characterization of $A u N P s$ and $D N A-A g N C s$}

The TEM results in Figure 1A indicate that the prepared AuNPs were spherical, well-dispersed, and their size was about $17 \mathrm{~nm}$. The UV-vis absorption spectrum of AuNPs illustrated that it had an absorption peak at approximately $518 \mathrm{~nm}$ (Figure 1B). Furthermore, it was observed that the maximum absorption wavelength of the synthesized AuNPs-cDNA2 probe was $526 \mathrm{~nm}$, indicating that it had been successfully prepared.
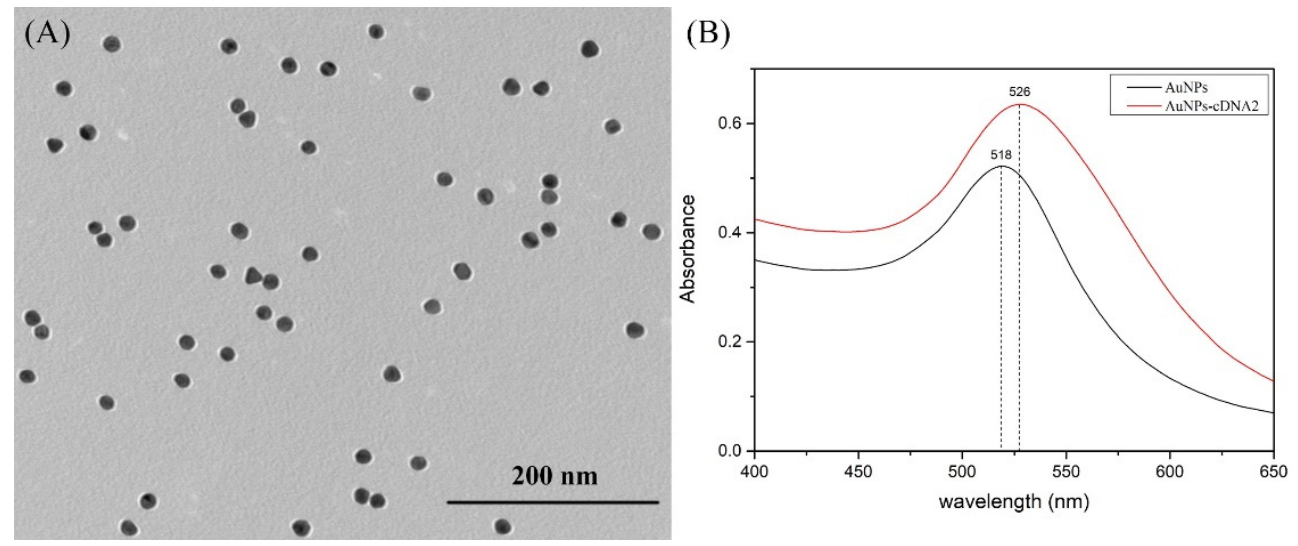

Figure 1. Characterization of colloidal gold. (A) The TEM image of AuNPs (Scale bar: $200 \mathrm{~nm}$ ). (B) UV-visible absorption spectra of AuNPs and AuNPs-cDNA2 probe. 
As revealed from Figure 2A, the prepared AgNCs complex had a characteristic absorption band at $576 \mathrm{~nm}$. When the excitation wavelength was $576 \mathrm{~nm}$, the apparent fluorescence emission appeared at $643 \mathrm{~nm}$ (Figure 2B). Meanwhile, the solution displayed an obvious orangey-red color under the UV irradiation. The TEM image indicated that the DNA-AgNCs were nearly global and the mean diameter was 2 5 nm, which is represented by dark clusters (Figure $2 \mathrm{C}$ ). In addition, the $\mathrm{Ag} 3 \mathrm{~d}$ region of XPS spectra showed that the material had two characteristic peaks, which were $\mathrm{Ag} 3 d_{5 / 2}$ at $368.0 \mathrm{eV}$ and $\mathrm{Ag} 3 \mathrm{~d}_{3 / 2}$ at $373.8 \mathrm{eV}$, respectively, indicating the presence of Ag elements (Figure 2D). The above results proved that the DNA-AgNCs synthesis was successful.
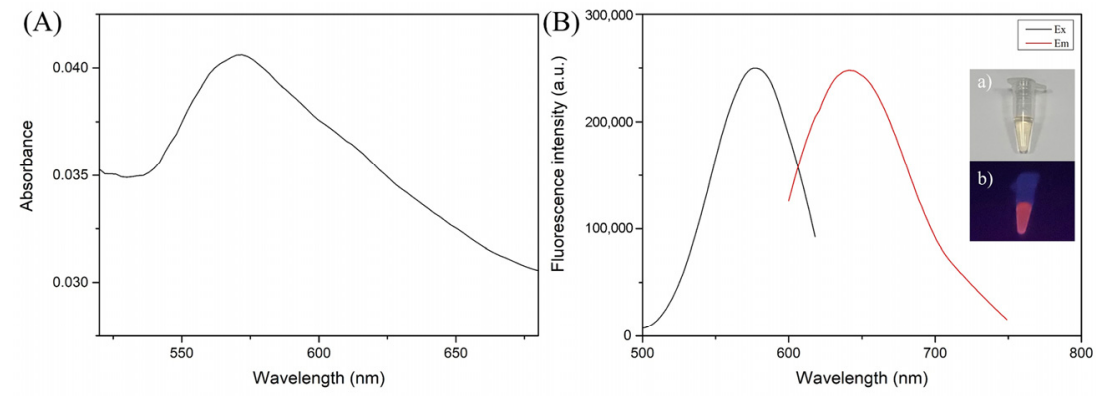

(C)

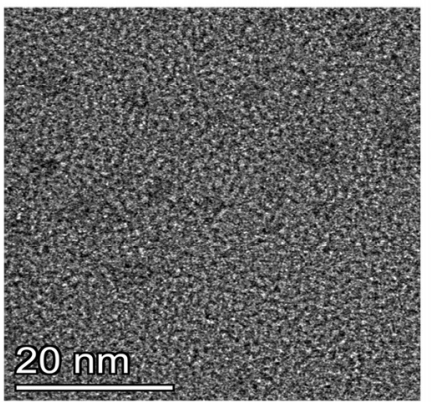

(D)

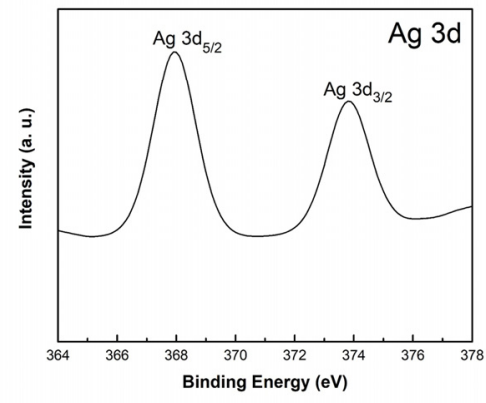

Figure 2. Synthesis of DNA-AgNCs characterization. (A) UV-vis absorption spectra of DNAAgNCs. (B) Excitation and emission spectra of DNA-AgNCs. Inset: photograph under the room light (a) and UV light (b). (C) TEM image of DNA-AgNCs (Scale bar: $20 \mathrm{~nm}$ ). (D) X-ray photoelectron spectroscopy.

\subsection{Feasibility Testing for Proposed Strategy}

As illustrated in Figure 3, fluorescence spectra were utilized to research the feasibility of this detection method. When the aptamer (curve c) or AuNPs-cDNA2 (curve d) was absent, the fluorescence quenching system could not be constructed. Therefore, when the DNA-AgNCs were added, there was no obvious change in the fluorescence intensity. Nevertheless, the fluorescence intensity was significantly reduced in the mixture of SMBs-cDNA1, aptamer, and AuNPs-cDNA2 (curve a). This phenomenon indicates that a complete fluorescence quenching system could lead to effective fluorescence quenching of DNA-AgNCs. Furthermore, a significant fluorescence enhancement was observed when $S$. Typhimurium was present in the sample (curve b). These outcomes demonstrate that the whole system can be applied to detect $S$. Typhimurium. 


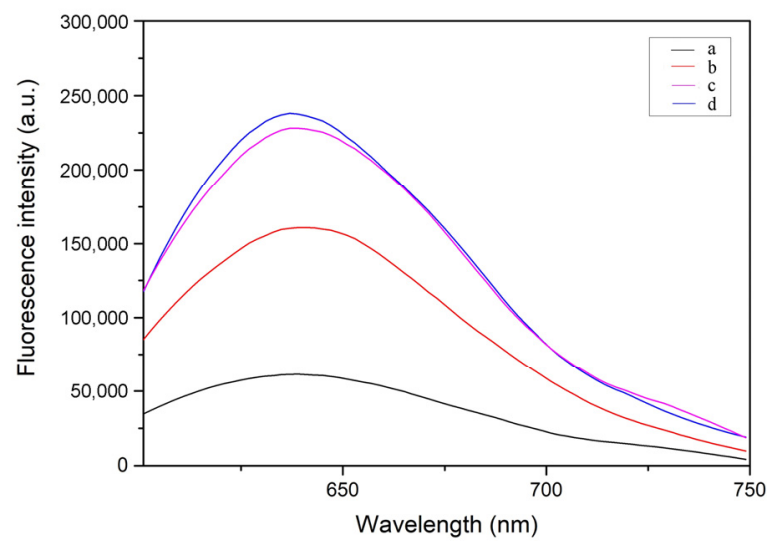

Figure 3. Fluorescence response of the reaction solution with different conditions: (a) SMBs-cDNA1+ Apt+AuNPs-cDNA2+DNA-AgNCs; (b) SMBs-cDNA1+Apt+AuNPs-cDNA2+S. Typhimurium+DNA -AgNCs; (c) SMBs-cDNA1+AuNPs-cDNA2+DNA-AgNCs; (d) SMBs-cDNA1+Apt+DNA-AgNCs. SMBs-cDNA1: $40 \mu \mathrm{g}$, Apt: $2.5 \mathrm{nM}$, AuNPs-cDNA2: $20 \mu \mathrm{L}, S$. Typhimurium: $10^{6} \mathrm{cfu} / \mathrm{mL}$, DNA -AgNCs: $20 \mu \mathrm{L}$.

\subsection{Optimization of Trial Conditions}

In this investigation, the aptamer was simultaneously hybridized with the SMBscDNA1 complex and AuNPs-cDNA2 probes in the fluorescence quenching system, and applied to combine with target bacteria. Thus, the concentration of aptamer played an important role in the assay. The lower concentration may result in less sandwich structure (SMBs-cDNA1 complex, aptamer, and AuNPs-cDNA2 probe) formation, and in the absence of $S$. Typhimurium, the fluorescence quenching system cannot be fully functional, resulting in fluorescence of DNA-AgNCs. Whereas, when the system contained a high concentration of aptamer, there was still surplus aptamer after the reaction with $S$. Typhimurium. This resulted in an excess sandwich structure and quenched part of the fluorescence intensity after adding DNA-AgNCs, making it insignificant. From the results in Figure 4A, we found that the fluorescence ratio $(1-\mathrm{F} 0 / \mathrm{F})$ steadily increased with the increasing concentration of aptamer, arriving at its maximum at $2.5 \mathrm{nM}$, and then decreasing. Based on the above, a $2.5 \mathrm{nM}$ aptamer was used throughout the experiment. Then, the amounts of SMBs-cDNA1 complex and AuNPs-cDNA2 probe were optimized for mixing with the aptamer. From Figure $4 \mathrm{~B}$, the $(1-\mathrm{F} 0 / \mathrm{F})$ increased with the growing amount of SMBs-cDNA1, and reached a plateau after $30 \mu \mathrm{g}$, before then decreasing at $50 \mu \mathrm{g}$. The reason for the decrease may be that the excessive SMBs-cDNA1 influenced the DNA-AgNCs. Figure 4C shows that the $(1-\mathrm{F} 0 / \mathrm{F})$ increased with an increasing amount of AuNPs-cDNA2 probe from 5 to $15 \mu \mathrm{L}$, and then remained unchanged at $20 \mu \mathrm{L}$. Thus, $30 \mu \mathrm{g}$ of the SMBs-cDNA1 complex and $15 \mu \mathrm{L}$ of the AuNPs-cDNA2 probe were selected for subsequent experiments. In addition, to construct the identification for $S$. Typhimurium in a short time, the reaction time of the fluorescence quenching system and the incubation time between the fluorescence quenching system and $S$. Typhimurium were optimized. As shown in Figure $4 \mathrm{D}, \mathrm{E}$, the optimal times for both reactions were $1 \mathrm{~h}$. 
(A)

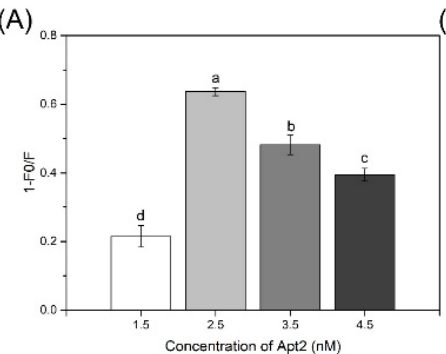

(D)
(B)

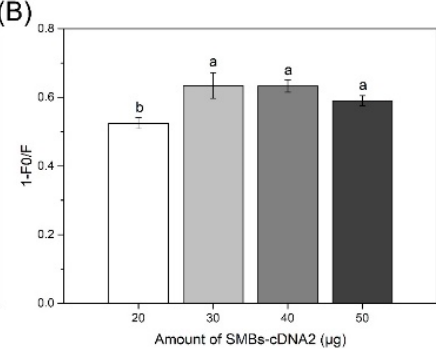

(C)

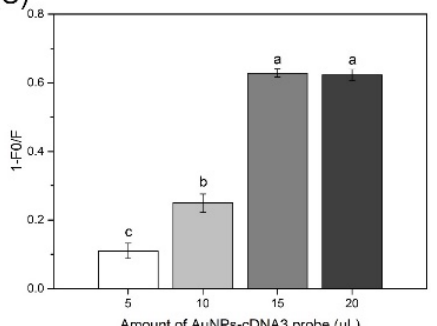

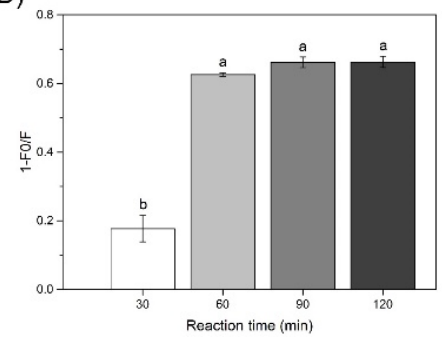

(E)

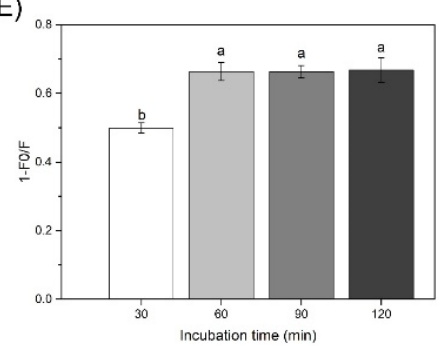

Figure 4. Optimization of trial conditions. (A) Concentration of aptamer. (B) Amount of SMBscDNA1 complex. (C) Amount of AuNPs-cDNA2 probe. (D) Reaction time between the SMBscDNA1 complex, the aptamer, and the AuNPs-cDNA2 probe (SMBs-Apt-AuNPs). (E) Incubation time of SMBs-Apt-AuNPs with $S$. Typhimurium. The error bars show the standard deviations of 3 replicates. Different lowercase letters indicate significant differences $(p<0.05)$. The concentration of $S$. Typhimurium was tested at $10^{6} \mathrm{cfu} / \mathrm{mL}$.

\subsection{Sensitivity Detection for S. Typhimurium}

The prepared system was conducted to detect different concentrations of $S$. Typhimurium under the best conditions, and the results are shown in Figure 5A. When the $S$. Typhimurium concentration increased from $3.7 \times 10^{2}$ to $3.7 \times 10^{8} \mathrm{cfu} / \mathrm{mL}$, the fluorescence intensity gradually increased. Meanwhile, there was a linear relationship between the fluorescence ratio $(1-\mathrm{F} 0 / \mathrm{F})$ and the logarithm of $S$. Typhimurium concentration in the range of $3.7 \times 10^{2}$ to $3.7 \times 10^{5} \mathrm{cfu} / \mathrm{mL}$ (Figure $5 \mathrm{~B}$ ). The linear regression equation was $y=0.1120 x+0.0307$, with a correlation coefficient of $R^{2}=0.9858$. According to the calculation formula, the limit of detection (LOD) was $98 \mathrm{cfu} / \mathrm{mL}, \mathrm{LOD}=3 \mathrm{~N} / \mathrm{S}$, where $\mathrm{N}$ is the standard deviation of the blank sample, and $\mathrm{S}$ is the slope of the standard curve. The whole detection could be finished within $2 \mathrm{~h} 10 \mathrm{~min}$. The reported methods for detecting $S$. Typhimurium with their line ranges and detection time are listed in Table 2. However, some of these approaches are time-consuming or have low detection lines. This method can greatly shorten the detection time on the premise of ensuring the detection limit. Therefore, this fluorescence aptasensor designed in this research provides a simple and rapid novel technique which can achieve low LOD.

To confirm the high selectivity of the developed fluorescence aptasensor, seven common non-S. Typhimurium bacteria were selected with the concentration of $10^{5} \mathrm{cfu} / \mathrm{mL}$ for detection under the same conditions. As shown in Figure 6, the (1-F0/F) of $S$. Typhimurium was much higher than that of other bacteria, indicating the constructed method had good specificity and selectivity for the target microorganism. This is primarily because of the specific recognition of $S$. Typhimurium by the aptamer. 

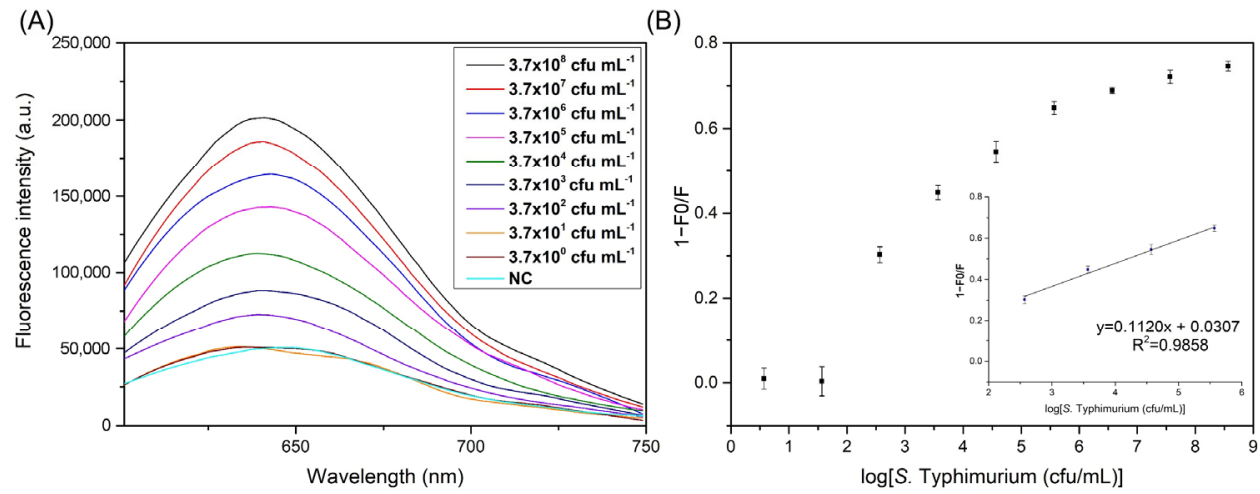

Figure 5. Sensitivity detection of the pure culture $S$. Typhimurium by established aptasensor. (A) The fluorescence emission spectra response with the concentrations of pure culture of $S$. Typhimurium ranged from $3.7 \times 10^{0}$ to $3.7 \times 10^{8} \mathrm{cfu} / \mathrm{mL}$. NC: negative control. (B) The relationship between the fluorescence ratio $(1-\mathrm{F} 0 / \mathrm{F})$ and the logarithm of the concentration of $S$. Typhimurium. Inset: the linear relationship between the $(1-\mathrm{F} 0 / \mathrm{F})$ and the logarithm of the concentration of $S$. Typhimurium. The error bars show the standard deviations of 3 repetitive experiments.

Table 2. Comparison with the previously reported methods for $S$. Typhimurium detection.

\begin{tabular}{|c|c|c|c|c|}
\hline Type of Sensor & Detection Limit (cfu/mL) & Linear Range (cfu/mL) & Detection Time & References \\
\hline Colorimetric aptasensor & 56 & $10^{2}$ to $10^{7}$ & $31 \mathrm{~h} 15 \mathrm{~min}$ & [8] \\
\hline Fluorescent aptasensor & 733 and 464 & 1530 to 96,938 & $30 \mathrm{~min}$ & [9] \\
\hline Colorimetric aptasensor & 1 & $10^{1}$ to $10^{6}$ & $8 \mathrm{~h}$ & [11] \\
\hline $\begin{array}{l}\text { Gold nanoparticles (AuNPs) } \\
\text { colorimetric sensor based on PCR assay }\end{array}$ & 33 & $3.3 \times 10^{1}$ to $3.3 \times 10^{6}$ & $3 \mathrm{~h}$ & [25] \\
\hline $\begin{array}{l}\text { Quartz crystal microbalance (QCM) } \\
\text { biosensor }\end{array}$ & $7.9 \times 10^{3}$ & $7.9 \times 10^{2}$ to $7.9 \times 10^{6}$ & $1 \mathrm{~h}$ & [33] \\
\hline Magnetic nanomaterial biosensor & 300 & 300 to 1000 & $1.5 \mathrm{~h}$ & [34] \\
\hline $\begin{array}{l}\text { Surface-enhanced Raman scattering } \\
\text { (SERS) aptasensor }\end{array}$ & 4 & $10^{1}$ to $10^{5}$ & $14 \mathrm{~h}$ & [35] \\
\hline Lateral flow immunoassay & $3.75 \times 10^{3}$ & $1.88 \times 10^{4}$ to $1.88 \times 10^{7}$ & $35 \mathrm{~min}$ & [36] \\
\hline This method & 98 & $3.7 \times 10^{2}$ to $3.7 \times 10^{5}$ & $2 \mathrm{~h} 10 \mathrm{~min}$ & \\
\hline
\end{tabular}

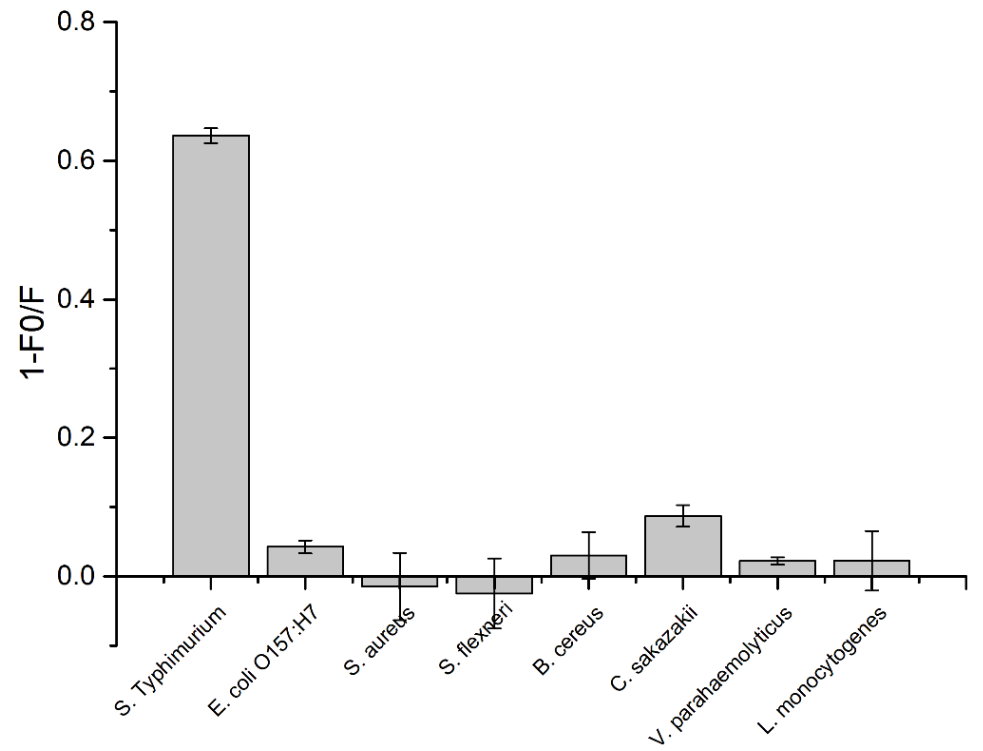

Figure 6. Specificity verification of the fluorescence aptasensor for $S$. Typhimurium and 7 non-S. Typhimurium bacteria. Error bars denote the standard deviation of 3 repetitive experiments. The concentration of $S$. Typhimurium was selected as $10^{5} \mathrm{cfu} / \mathrm{mL}$. 


\subsection{Sensitivity Test in Artificially Contaminated Milk Samples}

To prove the feasibility of the aptasensor, a series of serial dilutions of $S$. Typhimurium were used to prepare artificially contaminated milk. Figure 7A shows that when the $S$. Typhimurium concentration increased from $7.6 \times 10^{1}$ to $7.6 \times 10^{7} \mathrm{cfu} / \mathrm{mL}$, the fluorescence intensity increased step by step. A good linear relationship $\left(R^{2}=0.9754\right)$ was realized between the $(1-\mathrm{F} 0 / \mathrm{F})$ and the logarithm of the concentration of $S$. Typhimurium ranging from $7.6 \times 10^{3}$ to $7.6 \times 10^{6} \mathrm{cfu} / \mathrm{mL}$ (Figure 7B). The LOD was assessed to be $3.4 \times 10^{2} \mathrm{cfu} / \mathrm{mL}$. Compared with previously reported methods, this study showed a lower LOD [1,37]. These results illustrate that the fluorescence aptasensor is fit to determinate $S$. Typhimurium in artificially contaminated milk.
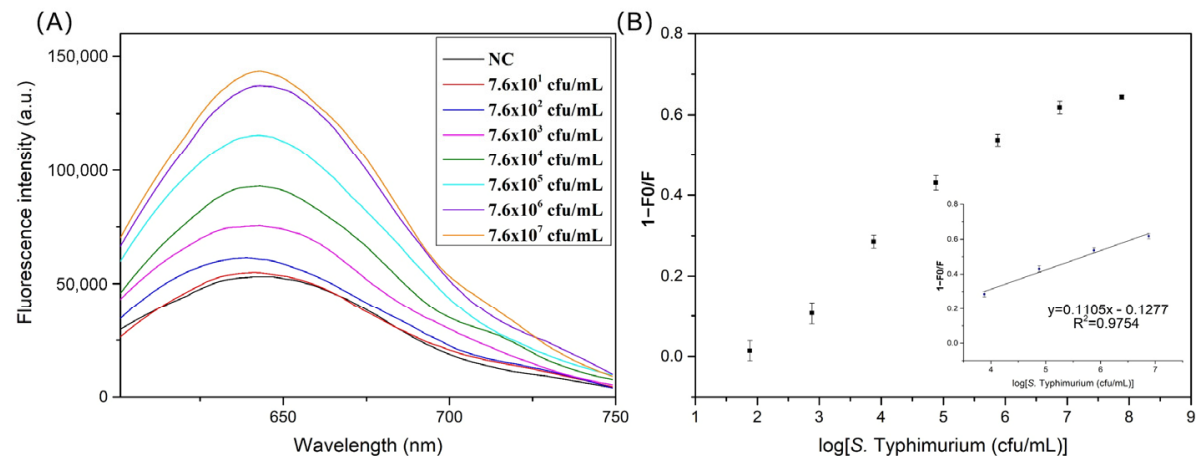

Figure 7. Sensitivity detection of $S$. Typhimurium in milk samples by an established aptasensor. (A) The fluorescence emission spectra response with the concentrations of $S$. Typhimurium in artificially contaminated milk ranged from $7.6 \times 10^{1}$ to $7.6 \times 10^{7} \mathrm{cfu} / \mathrm{mL}$. NC: negative control. (B) The relationship between the fluorescence ratio $(1-\mathrm{F} 0 / \mathrm{F})$ and the logarithm of the concentration of $S$. Typhimurium. Inset: the linear relationship between the $(1-\mathrm{F} 0 / \mathrm{F})$ and the logarithm of the concentration of $S$. Typhimurium. The error bars show the standard deviations of 3 repetitive experiments.

To further evaluate the reliability of the aptasensor, the recovery test was carried out by spiking known concentrations of $S$. Typhimurium into milk and the results were listed in Table 3. The recoveries were determined to be $92.9-108.7 \%$, indicating the potential practical application value of the novel fluorescence aptasensor for determination in complex foods.

Table 3. Recovery and relative standard deviation (RSD) of $S$. Typhimurium in artificially contaminated milk.

\begin{tabular}{ccccc}
\hline No. & Spiked (cfu/mL) & Found $(\mathbf{c f u} / \mathbf{m L})^{\mathbf{a}}$ & Recovery $(\%)$ & RSD (\%, $\mathbf{n}=\mathbf{3})$ \\
\hline 1 & $5.2 \times 10^{4}$ & $5.65 \times 10^{4}$ & 108.7 & 4.91 \\
2 & $5.2 \times 10^{5}$ & $5.08 \times 10^{5}$ & 97.7 & 1.88 \\
3 & $5.2 \times 10^{6}$ & $4.83 \times 10^{6}$ & 92.9 & 2.14 \\
\hline
\end{tabular}

a Average of three replicate measurements (rounded).

\section{Conclusions}

In conclusion, a label-free fluorescence aptasensor was set up for rapid, sensitive, and specific detection of $S$. Typhimurium due to the fluorescence change in DNA-AgNCs. The constructed fluorescence quenching system, including magnetic beads, an aptamer, and AuNPs, could effectively quench the DNA-AgNCs. In the presence of $S$. Typhimurium, the system was disrupted, leading to an obvious rise in fluorescence intensity. The results demonstrated that the developed aptasensor showed high selectivity and sensitivity for $S$. Typhimurium detection. At the same time, a good linear relationship was acquired when the concentrations of $S$. Typhimurium ranged from $3.7 \times 10^{2}$ to $3.7 \times 10^{5} \mathrm{cfu} / \mathrm{mL}$, with the LOD being $98 \mathrm{cfu} / \mathrm{mL}$. Furthermore, the aptasensor was capable of detecting $S$. Typhimurium successfully in artificially contaminated milk with a LOD of $3.4 \times 10^{2} \mathrm{cfu} / \mathrm{mL}$, indicating that this could be regarded as an effective tool for the determination of $S$. Ty- 
phimurium in complex foods. Importantly, the established system can detect diverse bacteria by changing the corresponding aptamers.

Author Contributions: Conceptualization, C.M. and Y.J.; methodology, S.F. and X.Y.; software, L.P.; validation, S.C.; formal analysis, D.S.; investigation, S.F. and X.Y.; data curation, X.Q.; writingoriginal draft preparation, S.F. and X.Y.; writing-review and editing, L.P. and S.C.; supervision, C.M.; project administration, Y.J.; funding acquisition, Y.J. All authors have read and agreed to the published version of the manuscript.

Funding: This research was funded by the Joint Funds of the National Natural Science Foundation of China (No. U21A20272) and the Natural Science Foundation of Heilongjiang Province of China (No. ZD2021C004).

Data Availability Statement: Data is contained within the article.

Conflicts of Interest: The authors declare no conflict of interest.

\section{References}

1. Srisa-Art, M.; Boehle, K.E.; Geiss, B.J.; Henry, C.S. Highly Sensitive and Rapid Detection of Salmonella typhimurium Using a Colorimetric Paper-Based Analytical Device Coupled with Immunomagnetic Separation. Anal. Chem. 2018, 90, 1035-1043. [CrossRef] [PubMed]

2. Jia, S.; McWhorter, A.R.; Andrews, D.M.; Underwood, G.J.; Chousalkar, K.K. Challenges in Vaccinating Layer Hens against Salmonella Typhimurium. Vaccines 2020, 8, 696. [CrossRef] [PubMed]

3. Lee, K.-M.; Runyon, M.; Herrman, T.J.; Phillips, R.; Hsieh, J. Review of Salmonella detection and identification methods: Aspects of rapid emergency response and food safety. Food Control 2015, 47, 264-276. [CrossRef]

4. Wang, S.; Zheng, L.; Cai, G.; Liu, N.; Liao, M.; Li, Y.; Zhang, X.; Lin, J. A microfluidic biosensor for online and sensitive detection of Salmonella typhimurium using fluorescence labeling and smartphone video processing. Biosens. Bioelectron. 2019, 140, 111333. [CrossRef] [PubMed]

5. Rohde, A.; Hammerl, J.A.; Boone, I.; Jansen, W.; Fohler, S.; Klein, G.; Dieckmann, R.; Al Dahouk, S. Overview of validated alternative methods for the detection of foodborne bacterial pathogens. Trends Food Sci. Technol. 2017, 62, 113-118. [CrossRef]

6. Zhao, Y.; Liu, R.; Sun, W.; Lv, L.; Guo, Z. Ochratoxin A detection platform based on signal amplification by Exonuclease III and fluorescence quenching by gold nanoparticles. Sens. Actuators B Chem. 2018, 255, 1640-1645. [CrossRef]

7. Yu, X.; Chen, F.; Wang, R.; Li, Y. Whole-bacterium SELEX of DNA aptamers for rapid detection of E.coli O157:H7 using a QCM sensor. J. Biotechnol. 2018, 266, 39-49. [CrossRef]

8. Ma, X.; Song, L.; Zhou, N.; Xia, Y.; Wang, Z. A novel aptasensor for the colorimetric detection of S. typhimurium based on gold nanoparticles. Int. J. Food Microbiol. 2017, 245, 1-5. [CrossRef]

9. Srinivasan, S.; Ranganathan, V.; DeRosa, M.C.; Murari, B.M. Label-free aptasensors based on fluorescent screening assays for the detection of Salmonella typhimurium. Anal. Biochem. 2018, 559, 17-23. [CrossRef]

10. Ranjbar, S.; Shahrokhian, S.; Nurmohammadi, F. Nanoporous gold as a suitable substrate for preparation of a new sensitive electrochemical aptasensor for detection of Salmonella typhimurium. Sens. Actuators B Chem. 2018, 255, 1536-1544. [CrossRef]

11. Chen, Q.; Gao, R.; Jia, L. Enhancement of the peroxidase-like activity of aptamers modified gold nanoclusters by bacteria for colorimetric detection of Salmonella typhimurium. Talanta 2021, 221, 121476. [CrossRef] [PubMed]

12. Xu, J.; Zhu, X.; Zhou, X.; Khusbu, F.Y.; Ma, C. Recent advances in the bioanalytical and biomedical applications of DNA-templated silver nanoclusters. TrAC Trends Anal. Chem. 2020, 124, 115786. [CrossRef]

13. Zou, R.; Zhang, F.; Chen, C.; Cai, C. DNA-programming multicolor silver nanoclusters for sensitively simultaneous detection of two HIV DNAs. Sens. Actuators B Chem. 2019, 296, 126608. [CrossRef] [PubMed]

14. Zhang, M.; Gao, G.; Ding, Y.; Deng, C.; Xiang, J.; Wu, H. A fluorescent aptasensor for the femtomolar detection of epidermal growth factor receptor-2 based on the proximity of G-rich sequences to Ag nanoclusters. Talanta 2019, 199, 238-243. [CrossRef]

15. Saraswathi, S.K.; Vittala, S.K.; Manayani, M.K.; Joseph, J. Sequence programmed DNA three-way junctions for templated assembly of fluorescent silver nanoclusters. J. Photochem. Photobiol. B Biol. 2020, 207, 111886. [CrossRef]

16. Feng, X.; Han, T.; Xiong, Y.; Wang, S.; Dai, T.; Chen, J.; Zhang, X.; Wang, G. Plasmon-Enhanced Electrochemiluminescence of Silver Nanoclusters for microRNA Detection. ACS Sens. 2019, 4, 1633-1640. [CrossRef]

17. Lee, C.Y.; Lin, S.W.; Wu, Y.H.; Hsieh, Y.Z. Combining DNA-stabilized silver nanocluster synthesis with exonuclease III amplification allows label-free detection of coralyne. Anal. Chim. Acta 2018, 1042, 86-92. [CrossRef]

18. Lee, S.Y.; Fazlina, N.; Tye, G.J. DNA-templated silver nanocluster for live-intracellular FOXP3 detection. Anal. Biochem. 2019, 581, 113352. [CrossRef]

19. Esmaelpourfarkhani, M.; Abnous, K.; Taghdisi, S.M.; Chamsaz, M. A novel turn-off fluorescent aptasensor for ampicillin detection based on perylenetetracarboxylic acid diimide and gold nanoparticles. Biosens. Bioelectron. 2020, 164, 112329. [CrossRef] 
20. Asnaashari, M.; Esmaeilzadeh Kenari, R.; Farahmandfar, R.; Taghdisi, S.M.; Abnous, K. Fluorescence quenching biosensor for acrylamide detection in food products based on double-stranded DNA and gold nanoparticles. Sens. Actuators B Chem. 2018, 265, 339-345. [CrossRef]

21. Ma, J.L.; Yin, B.C.; Le, H.N.; Ye, B.C. Label-Free Detection of Sequence-Specific DNA Based on Fluorescent Silver NanoclustersAssisted Surface Plasmon-Enhanced Energy Transfer. ACS Appl. Mater. Interfaces 2015, 7, 12856-12863. [CrossRef] [PubMed]

22. Miao, X.; Cheng, Z.; Ma, H.; Li, Z.; Xue, N.; Wang, P. Label-Free Platform for MicroRNA Detection Based on the Fluorescence Quenching of Positively Charged Gold Nanoparticles to Silver Nanoclusters. Anal. Chem. 2018, 90, 1098-1103. [CrossRef] [PubMed]

23. Yang, X.; Wang, L.; Pang, L.; Fu, S.; Qin, X.; Chen, Q.; Man, C.; Jiang, Y. A novel fluorescent platform of DNA-stabilized silver nanoclusters based on exonuclease III amplification-assisted detection of Salmonella Typhimurium. Anal. Chim. Acta 2021, 1181, 338903. [CrossRef] [PubMed]

24. Mao, X.; Ma, Y.; Zhang, A.; Zhang, L.; Zeng, L.; Liu, G. Disposable Nucleic Acid Biosensors Based on Gold Nanoparticle Probes and Lateral Flow Strip. Anal. Chem. 2009, 81, 1660-1668. [CrossRef] [PubMed]

25. Chen, S.; Yang, X.; Fu, S.; Qin, X.; Yang, T.; Man, C.; Jiang, Y. A novel AuNPs colorimetric sensor for sensitively detecting viable Salmonella typhimurium based on dual aptamers. Food Control 2020, 115, 107281. [CrossRef]

26. Zhu, X.; Xu, H.; Li, W.; Dong, Y.; Chi, Y. A novel hybrid platform of g-C3N4 nanosheets / nucleic-acid-stabilized silver nanoclusters for sensing protein. Anal. Chim. Acta 2019, 1091, 112-118. [CrossRef]

27. ISO 6579-1:2017; Microbiology of the Food Chain-Horizontal Method for the Detection, Enumeration and Serotyping of Salmonella-Part 1: Detection of Salmonella spp. International Organization for Standardization: Geneva, Switzerland, 2017.

28. Li, S.; Fu, Y.; Ma, X.; Zhang, Y. Label-free fluorometric detection of chymotrypsin activity using graphene oxide/nucleic-acidstabilized silver nanoclusters hybrid materials. Biosens. Bioelectron. 2017, 88, 210-216. [CrossRef]

29. Zhang, S.; Wang, K.; Li, K.-B.; Shi, W.; Jia, W.-P.; Chen, X.; Sun, T.; Han, D.-M. A DNA-stabilized silver nanoclusters/graphene oxide-based platform for the sensitive detection of DNA through hybridization chain reaction. Biosens. Bioelectron. 2017, 91, 374-379. [CrossRef]

30. Xue, N.; Wu, S.; Li, Z.; Miao, X. Ultrasensitive and label-free detection of ATP by using gold nanorods coupled with enzyme assisted target recycling amplification. Anal. Chim. Acta 2020, 1104, 117-124. [CrossRef]

31. Lerga, T.M.; Skouridou, V.; Bermudo, M.C.; Bashammakh, A.S.; El-Shahawi, M.S.; Alyoubi, A.O.; O'Sullivan, C.K. Gold nanoparticle aptamer assay for the determination of histamine in foodstuffs. Microchim. Acta 2020, 187, 452. [CrossRef]

32. Kimura-Suda, H.; Petrovykh, D.Y.; Tarlov, M.J.; Whitman, L.J. Base-Dependent Competitive Adsorption of Single-Stranded DNA on Gold. J. Am. Chem. Soc. 2003, 125, 9014-9015. [CrossRef] [PubMed]

33. Wang, L.; Wang, R.; Chen, F.; Jiang, T.; Wang, H.; Slavik, M.; Wei, H.; Li, Y. QCM-based aptamer selection and detection of Salmonella typhimurium. Food Chem. 2017, 221, 776-782. [CrossRef] [PubMed]

34. Zhang, Z.; Wang, Q.; Han, L.; Du, S.; Yu, H.; Zhang, H. Rapid and sensitive detection of Salmonella typhimurium based on the photothermal effect of magnetic nanomaterials. Sens. Actuators B Chem. 2018, 268, 188-194. [CrossRef]

35. Ma, X.; Xu, X.; Xia, Y.; Wang, Z. SERS aptasensor for Salmonella typhimurium detection based on spiny gold nanoparticles. Food Control 2018, 84, 232-237. [CrossRef]

36. Hu, J.; Jiang, Y.Z.; Tang, M.; Wu, L.L.; Xie, H.Y.; Zhang, Z.L.; Pang, D.W. Colorimetric-Fluorescent-Magnetic Nanosphere-Based Multimodal Assay Platform for Salmonella Detection. Anal. Chem. 2019, 91, 1178-1184. [CrossRef] [PubMed]

37. Wang, W.; Liu, L.; Song, S.; Tang, L.; Kuang, H.; Xu, C. A highly sensitive ELISA and immunochromatographic strip for the detection of Salmonella typhimurium in milk samples. Sensors 2015, 15, 5281-5292. [CrossRef] 